\section{Original Article}

Korean J Transplant 2021;35:247-252 https://doi.org/10.4285/kjt.21.0030
Received November 23, 2021

Revised December 6, 2021

Accepted December 7, 2021

Corresponding author: Shin Hwang Department of Surgery, Asan Medical Center, University of Ulsan College of Medicine, 88 Olympic-ro 43-gil, Songpagu, Seoul 05505, Korea

Tel: +82-2-3010-3930

Fax: +82-2-3010-6701

E-mail: shwang@amc.seoul.kr

(C) The Korean Society for Transplantation This is an Open Access article distributed under the terms of the Creative Commons Attribution Non-Commercial License (http://creativecommons.org/licenses/ by-nc/4.0/) which permits unrestricted non-commercial use, distribution, and reproduction in any medium, provided the original work is properly cited.

\section{$\mathrm{KJT}^{\mathrm{K}}$ \\ KOREAN JOURNAL OF TRANSPLANTATION}

pISSN 2671-8790

elSSN 2671-8804

\title{
An analysis of the number of liver and kidney transplantations during COVID-19 pandemic in Korea
}

\author{
Jung-Ja Hong ${ }^{1}$, Shin Hwang ${ }^{1,2}$, Deog-Bok Moon², Young Hoon Kim² ${ }^{2}$ Sung Shin², \\ In-Ok Kim', Sae-Rom Lee', Ah-Young Lee ${ }^{1}$, Jiwon Woo ${ }^{1}$ \\ ${ }^{1}$ Organ Transplantation Center, Asan Medical Center, University of Ulsan College of Medicine, Seoul, Korea \\ ${ }^{2}$ Department of Surgery, Asan Medical Center, University of Ulsan College of Medicine, Seoul, Korea
}

Background: The severity of the coronavirus disease 2019 (COVID-19) pandemic has discouraged organ donation. However, the prevalence of COVID-19 in Korea was much lower in comparison to Western countries. With this, the authors decided to determine the real-world impact of COVID-19 on organ donation and transplantation in Korea.

Methods: The number of kidney transplantations (KTs) and liver transplantations (LTs) performed in 2020 were compared with those in 2019 using the Korean Network for Organ Sharing database and Asan Medical Center (AMC) database.

Results: The annual number of deceased donors (DDs) was 450 in 2019 compared to 478 in 2020. Monthly DD number was $37.5 \pm 5.9$ in 2019 and $39.8 \pm 4.4$ in $2020(P=0.284)$. Annual number of DD kidney transplant (DDKT) was 794 in 2019 and 848 in 2020, and monthly number was $66.1 \pm 10.4$ in 2019 and $70.7 \pm 9.8$ in $2020(P=0.285)$. The annual number of DDLT was 391 in 2019 and 395 in 2020, and the monthly number was $32.6 \pm 5.7$, 2019 and $32.9 \pm 4.7$ in $2020(P=0.877)$. The annual number of living donor $(L D) K T$ was 2,293 in 2019 and 1,432 in 2020, and the monthly number was $191.1 \pm 19.5$ in 2019 and $119.3 \pm 11.7$ in $2020(P<0.001)$. Annual number of living donor LDLT was 1,577 in 2019 and 1,146 in 2020, and monthly number was $131.4 \pm 18.1$ in 2019 and $95.5 \pm 8.0$ in 2020 $(P<0.001)$. In the AMC, not all types of KT and LT changed significantly.

Conclusions: The results of this study indicate that the number of DD organ transplantations remained stable in Korea in 2020, but the number of LD organ transplantations was significantly reduced. However, the number of organ transplantations did not change in the AMC.

Keywords: COVID-19; Deceased donor; Living donor; Organ transplantation; Donation promotion 


\section{HIGHLIGHTS}

- Under coronavirus disease 2019 (COVID-19), the number of deceased donor organ transplantations remained stable in Korea during 2020, but the number of living donor organ transplantations significantly reduced.

- However, organ transplantation number was not changed in Asan Medical Center.

\section{INTRODUCTION}

The severe acute respiratory syndrome coronavirus 2 (SARS-CoV-2) pandemic occurred in 2019 (coronavirus disease 2019 [COVID-19]). This impacted all facets of the Korean healthcare system, including life-saving procedures such as organ transplantation. Concerns for potential exposure to SARS-CoV-2 have profoundly altered the process of organ donation and recovery, which is vital to organ transplantation [1-4]. In 2020, COVID-19 substantially impacted on transplant community since the possibility of virus transmission from donors to recipients or donors to health workers have altered the capacity for safe recovery of organs and transplantation.

Western countries have experienced a significant decline in the number of deceased donors and organ transplantations due to increasing COVID-19 infections [4-9]. In comparison, the prevalence of COVID-19 was much lower

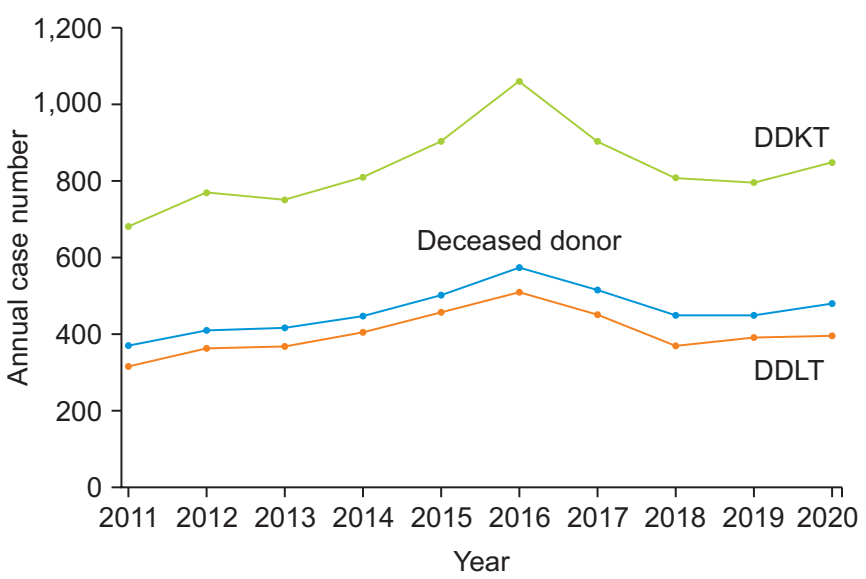

Fig. 1. The annual incidence of deceased donors and deceased donor organ transplantation in Korea from the year 2011 to 2020. Deceased donor kidney transplantation (DDKT) and deceased donor liver transplantation (DDLT) indicate deceased donor kidney and liver transplantation, respectively. in the general population of Korea. Furthermore, the number of critically ill patients in Korea was substantially lesser than that of Western countries [10-12]. That being the case, it is necessary to know if the pandemic has affected the number of organ donations and transplantations in Korea. The study aims to determine the number of deceased organ donors and deceased kidney and liver transplantations during the year 2020 using the Korean Network for Organ Sharing (KONOS) and Asan Medical Center databases.

\section{METHODS}

The study protocol was approved by the Institutional Review Board of Asan Medical Center (IRB No. 2021-1347), which waived the requirement for informed consent due to the retrospective nature of this study and the use of publicly available data. This study was performed in accordance with the ethical guidelines of the World Medical Association Declaration of Helsinki 2013.

The purpose of this study was to determine the annual number of KTs and LTs that occurred in Korea in 2020. The annual number of KTs and LTs in the year 2020 were compared with those in 2019 using the KONOS database and the Asan Medical Center organ transplantation database. Student t-test was utilized to compare the number of organ donations and transplantations. Statistical significance was set at $P<0.05$. All statistical analyses were performed using SPSS ver. 22 (IBM Corp., Armonk, NY, USA).

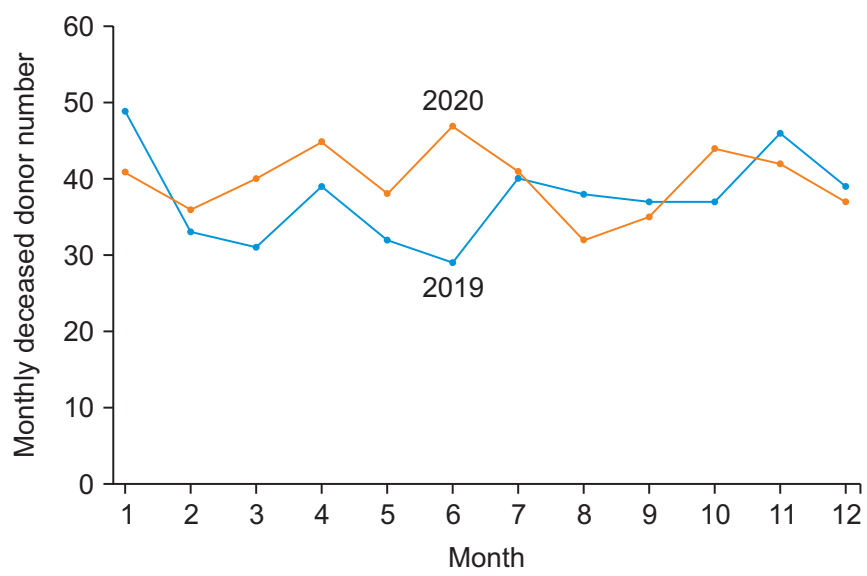

Fig. 2. Comparison of the monthly incidence of deceased donors between the year 2019 and 2020 in Korea. 


\section{RESULTS}

\section{Comparison of the Annual Number of Deceased Organ Donors and Deceased Donor Liver Transplant}

The total number of deceased organ donors during the 10-year period from 2011 to 2020 was 4,605. The annual incidence of deceased donors and deceased donor liver transplant (DDLT) is shown in Fig. 1.

\section{Comparison of the Monthly Number of Deceased Donors} and Deceased Donor Kidney and Liver Transplantations between the Year 2019 and 2020

The annual number of deceased donors was 450 in 2019 and 478 in 2020 . The average monthly number of deceased donors was $37.5 \pm 5.9$ in 2019 compared to $39.8 \pm 4.4$ in 2020 ( $P=0.284)$ (Fig. 2). The annual number of deceased donor kidney transplantation (DDKT) was 794 in 2019 and 848 in 2020. The average monthly number of DDKT was $66.1 \pm 10.4$ in 2019 compared to $70.7 \pm 9.8$ in $2020(\mathrm{P}=0.285)$ (Fig. 3A). The annual number of DDLT was 391 in 2019 and 395 in 2020 . The average monthly cases of DDLT was $32.6 \pm 5.7$ in 2019 compared to $32.9 \pm 4.7$ in 2020 ( $P=0.877)$ (Fig. 3B).

Three peaks in the incidence of COVID-19 infection during the year 2020 were observed namely FebruaryMarch, August-September, and November-December (Supplementary Fig. 1) [13]. However, the monthly case numbers of the deceased donors, DDKT, and DDLT, were
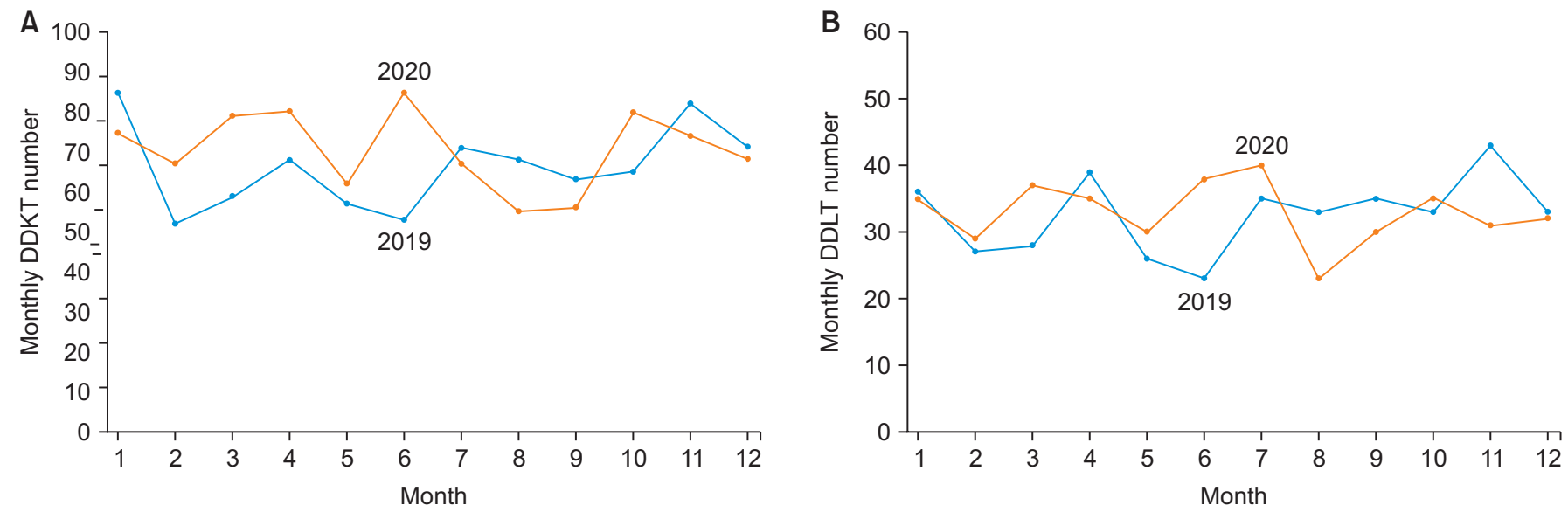

Fig. 3. (A) Comparison of the monthly incidences of deceased donor kidney transplantation (DDKT) and (B) deceased donor liver transplantation (DDLT) between the year 2019 and 2020 in Korea.
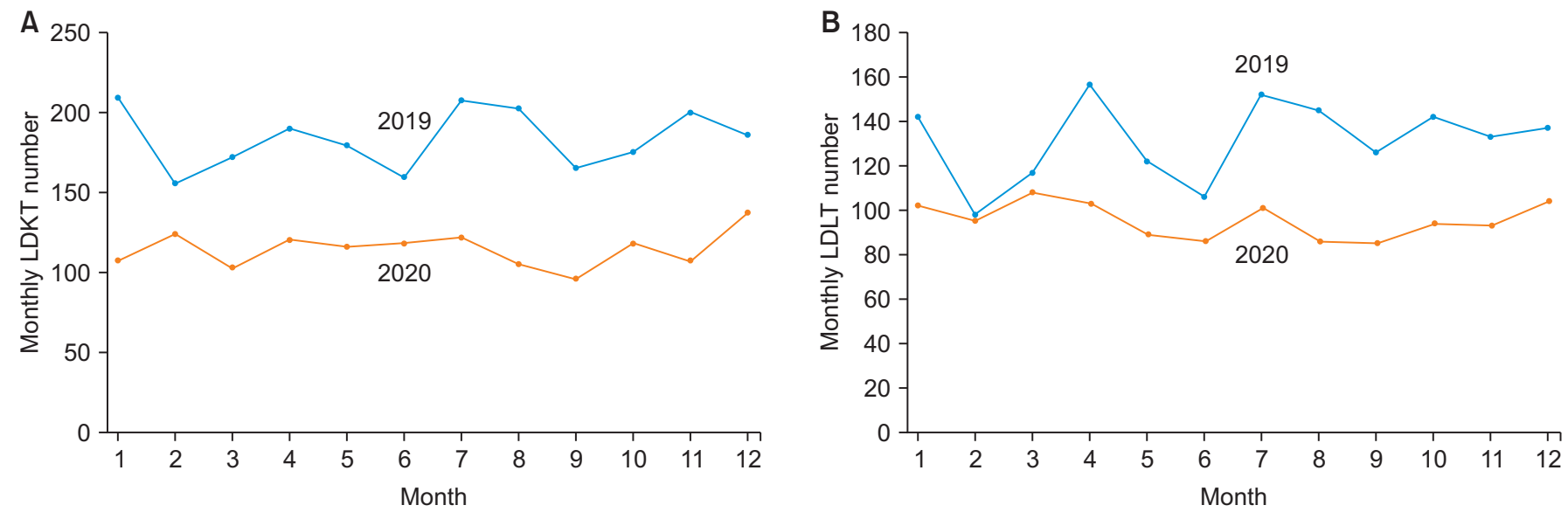

Fig. 4. (A) Comparison of the monthly incidences of living donor kidney transplantation (LDKT) and (B) living donor liver transplantation (LDLT) between the year 2019 and 2020 in Korea. 
not influenced by these peaks. These results indicate that the COVID-19 pandemic did not significantly affect the incidence of DDKT and DDLT in 2020.

\section{Comparison of the Monthly Number of Living Donor Kidney and Liver Transplantations between the Year 2019 and 2020}

The annual number of living donor kidney transplantation (LDKT) was 2,293 in 2019 and 1,432 in 2020. The average monthly cases of LDKT was $191.1 \pm 19.5$ in 2019 compared to $119.3 \pm 11.7$ in $2020(P<0.001)$ (Fig. 4A). The annual number of living donor liver transplantation (LDLT) was 1,577 in 2019 and 1,146 in 2020 . The average monthly cases of LDLT was $131.4 \pm 18.1$ in 2019 compared to $95.5 \pm 8.0$ in $2020(P<0.001)$ (Fig. 4B). These findings suggest that the COVID-19 pandemic has significantly decreased the incidence of LDKT and LDLT performed in 2020. A comparison of the incidence according to the deceased and living donor kidney and liver transplantations is depicted in Fig. 5.

\section{Comparison of Incidences of Deceased and Living Donor Kidney and Liver Transplantation between 2019 and 2020 in Asan Medical Center}

The annual number of DDKT cases was 90 in 2019 and 74 in 2020. The average monthly cases of DDKT was $7.5 \pm 2.4$ in 2019 compared to $6.2 \pm 1.9$ in $2020(P=0.145)$. The annual number of DDLT cases was 85 in 2019 and 85 in 2020. The average monthly cases of DDLT was $7.1 \pm 3.9$ in 2019 compared to $7.1 \pm 2.4$ in 2020 ( $P=0.982)$. The annual number of LDKT cases was 319 in 2019 compared to 333 in

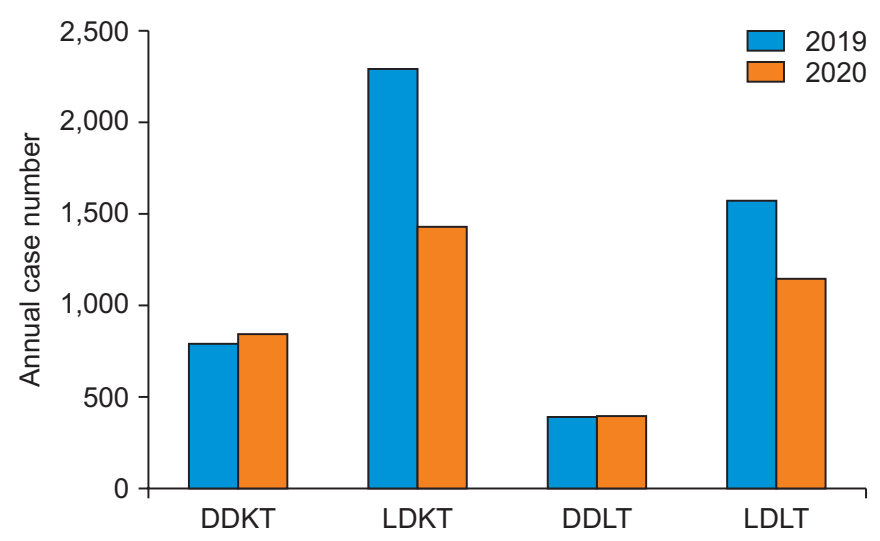

Fig. 5. Comparison of the number of deceased and living donor kidney and liver transplantations between the year 2019 and 2020 in Korea. DDKT, deceased donor kidney transplantation; LDKT, living donor kidney transplantation; DDLT, deceased donor liver transplantation; LDLT, living donor liver transplantation.
2020. The average monthly cases of LDKT was $26.6 \pm 3.3$ in 2019 compared to $27.8 \pm 3.1$ in $2020(P=0.375)$. The annual number of LDLT cases was 420 in 2019 compared to 399 in 2020. The average monthly cases of LDLT was $35.0 \pm 3.8$ in 2019 compared to $33.3 \pm 3.7$ in $2020(P=0.263)$. These findings suggest that the COVID-19 pandemic had no significant effect in the incidence of KTs and LTs regardless of donor type in Asan Medical Center. A comparison between the incidences of deceased and living donor kidney and liver transplantations is depicted in Fig. 6.

\section{DISCUSSION}

The World Health Organization declared COVID-19 a global pandemic as it spread rapidly worldwide. As there is no effective treatment for COVID-19, the risk of infection is high in patients awaiting transplant surgery for end-stage organ diseases. In addition, the procurement of organs recovered from deceased donors has decreased as the pandemic progresses. Moreover, living donor organ transplantations have been postponed to re-allocate medical resources for COVID-19 and to avoid nosocomial infection [4-8]. During the COVID-19 pandemic, decision-making regarding whether to proceed with organ transplantation has become a challenge. The COVID-19 pandemic has lasted for more than 1 and a half years; therefore, it is necessary to determine its impact on organ transplantation in Korea.

The results of this study indicate that in 2020 , there

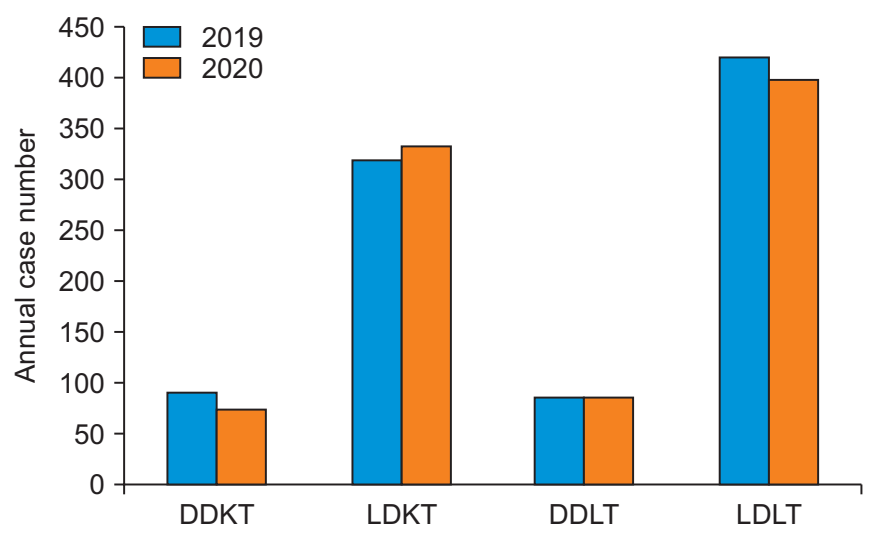

Fig. 6. Comparison of the number of deceased and living donor kidney and liver transplantations between the year 2019 and 2020 in Asan Medical Center. DDKT, deceased donor kidney transplantation; LDKT, living donor kidney transplantation; DDLT, deceased donor liver transplantation; LDLT, living donor liver transplantation. 
was no significant effect on the number of deceased donors and DDKT/DDLT in Korea, despite being significantly affected by the COVID-19 pandemic. On the other hand, comparison with data from 2019 shows a significant decrease in the number of LDKT and LDLT in Korea during the COVID-19 pandemic. Meanwhile, Lee et al. [14] reported an analysis of the transplantation activities in Severance Hospital and found that organ transplantations that were conducted with living and deceased donors remained stable during the COVID-19 outbreak, as compared to the same period in 2019. Similarly, no significant reduction in organ transplantation was observed in Asan Medical Center in the present study. In 2020, 56 transplant centers performed LT in Korea. Five high-volume centers accounted for $45.3 \%$ of the nationwide DDLT cases and $65.1 \%$ of the nationwide LDLT cases in 2020 [15]. In addition, four centers have performed more than 100 cases of DDLT and LDLT every year. These data indicate that the effect of the COVID-19 pandemic on LTs and KTs might be less significant in high-volume centers compared to low-volume centers. The authors presume that such a reduced impact is attributed to sufficient human resources and intensive care systems for organ transplantation in high-volume centers.

The burden of the COVID-19 pandemic was overwhelming on the healthcare system of Western countries, severely declining the rates of organ donation and transplantation. In the United States of America, a short-term analysis on the impact of COVID-19 on organ transplantation was conducted. The results indicated a strong temporal association between an increase in COVID-19 infections and a striking reduction in the overall number of solid-organ transplantation procedures $[8,9]$. The same decline has also been observed in several European countries [4-9]. Following the outbreak of COVID-19, the overall reduction in deceased donor transplantations was $90.6 \%$ and $51.1 \%$ in France and the USA respectively [8]. In both countries, this reduction was mostly observed in the number of KTs [9].

The impact of the COVID-19 pandemic on organ transplantation has been different between Western countries and Korea. This is primarily caused by a much higher prevalence of COVID-19 in the general population and number of critically ill patients in Western countries. A Korean epidemiologic study revealed that the national COVID-19 death rate was 2.3 per 100,000 [10], which is significantly lower compared to Western countries $[11,12]$.

However, the present study had several limitations. This was a retrospective cohort study with limited information on donors and recipients due to detailed data not being available in the KONOS database. In addition, the results of this study need to be validated through yearly follow-up studies, including data analysis for the year 2021.

In conclusion, the results of this study indicate that the number of DDKT and DDLT remained stable in 2020 despite the effects of the COVID-19 pandemic. On the other hand, a significant reduction in LDKT and LDLT was observed. In Asan Medical Center, however, no decrease in the number of organ transplantations was noted. Further studies are necessary to validate the results of the present study.

\section{ACKNOWLEDGMENTS}

\section{Conflict of Interest}

No potential conflict of interest relevant to this article was reported.

\section{Funding/Support}

This study was supported by the Research Fund of the Asan Medical Center Organ Transplantation Center (202101 to Shin Hwang).

This study was supported by research grant from the Korean Society for Transplantation (2021-00-01011-022).

\section{ORCID}

Jung-Ja Hong https://orcid.org/0000-0002-8219-3170 Shin Hwang https://orcid.org/0000-0002-9045-2531 Deok-Bog Moon https://orcid.org/0000-0002-8209-3540 Young Hoon Kim https://orcid.org/0000-0003-3840-8426 Sung Shin https://orcid.org/0000-0001-7318-4208 In-Ok Kim https://orcid.org/0000-0001-8615-9191 Sae-Rom Lee https://orcid.org/0000-0003-2586-0448 Ah-Young Lee https://orcid.org/0000-0002-7203-2381 Jiwon Woo https://orcid.org/0000-0003-3349-4134

\section{Author Contributions}

Conceptualization: SH, JJH. Data curation: DBM, YHK, SS. Formal analysis: JJH, IOK, SRL, AYL, JW. Funding acquisition: SH. Methodology: DBM, YHK, SS. Project administration: SH. Visualization: JJH. Writing-original draft: JJH, SH. Writing-review \& editing: all authors.

\section{Supplementary Materials}

Supplementary materials can be found via https://doi. 
org/10.4285/kjt.21.0030.

\section{REFERENCES}

1. Azzi Y, Bartash R, Scalea J, Loarte-Campos P, Akalin E. COVID-19 and solid organ transplantation: a review article. Transplantation 2021;105:37-55.

2. Sahin TT, Akbulut S, Yilmaz S. COVID-19 pandemic: its impact on liver disease and liver transplantation. World J Gastroenterol 2020;26:2987-99.

3. Domínguez-Gil $B$, Coll E, Fernández-Ruiz M, Corral E, Del Río F, Zaragoza R, et al. COVID-19 in Spain: transplantation in the midst of the pandemic. Am J Transplant 2020;20:2593-8.

4. Domínguez-Gil $B$, Fernández-Ruiz $M$, Hernández $D$, Crespo $\mathrm{M}$, Colmenero J, Coll E, et al. Organ donation and transplantation during the COVID-19 pandemic: a summary of the Spanish experience. Transplantation 2021;105:29-36.

5. Turco C, Lim C, Soubrane O, Malaquin G, Kerbaul F, Bastien O, et al. Impact of the first Covid-19 outbreak on liver transplantation activity in France: a snapshot. Clin Res Hepatol Gastroenterol 2021;45:101560.

6. Cannavò A, Passamonti SM, Martinuzzi D, Longobardi A, Fiorattini A, Troni NM, et al. The impact of COVID-19 on solid organ donation: the North Italy Transplant program experience. Transplant Proc 2020;52:2578-83.

7. Merola J, Schilsky ML, Mulligan DC. The impact of COVID-19 on organ donation, procurement and liver transplantation in the United States. Hepatol Commun 2020;5:5-11.

8. Loupy A, Aubert O, Reese PP, Bastien O, Bayer F, Jacquelinet $C$. Organ procurement and transplantation during the COVID-19 pandemic. Lancet 2020;395:e956.

9. Park CS, Park YH. Impact of COVID-19 on the number of deceased donors and organ transplantation in Western countries. Ann Liver Transplant 2021;1:123-8.

10. Kim DH, Park SJ, Kang HJ, Yeom EJ, Yoo NE, Lee JM, et al. Factors related to COVID-19 incidence and mortality rate in Gyeongsangbuk-do, Korea. J Agric Med Community Health 2020;45:235-44.

11. Rivera R, Rosenbaum JE, Quispe W. Excess mortality in the United States during the first three months of the COVID-19 pandemic. Epidemiol Infect 2020;148:e264.

12. Baud D, Qi X, Nielsen-Saines K, Musso D, Pomar L, Favre G. Real estimates of mortality following COVID-19 infection. Lancet Infect Dis 2020;20:773.

13. Corona Virus Resource Center. South Korea [Internet]. Baltimore, MD: Johns Hopkins University \& Medicine; 2021 [cited 2021 Dec 6]. Available from: https://coronavirus.jhu.edu/region/south-korea.

14. Lee J, Kim EJ, Ihn K, Lee JG, Joo DJ, Kim MS, et al. The feasibility of organ transplantation during the COVID-19 outbreak: experiences from South Korea. Korean J Transplant 2020;34:257-64.

15. Chung YK, Kang SH. Analysis of nationwide volume of liver transplantation in Korea during 2020 shows no definitive decrease during COVID-19 outbreak. Ann Liver Transplant 2021;1:135-9. 